Erin Parrish Reade • Craig Whaley • Jen-Jar Lin • Daniel W. McKenney $\cdot$ Daniel Lee $\cdot$ Ronald Perkin

\title{
Hypopnea in pediatric patients with obesity hypertension
}

Received: 8 September 2003 / Revised: 13 April 2004 / Accepted: 13 April 2004 / Published online: 4 June 2004 (C) IPNA 2004

\begin{abstract}
Obesity is associated with the development of hypertension but it is still not clear why hypertension is not observed in all obese patients. Obesity is a risk factor for the development of obstructive sleep apnea syndrome (OSAS) in children. OSAS has been linked to the development of hypertension in adults and children. The purpose of this study was to test the hypothesis that OSAS is one of the reasons that some obese children are hypertensive and some are not. The overnight polysomnography records of 90 patients (aged 4.2-18.8 years) were reviewed. $\mathrm{BMI}_{\text {score }}$ [body mass index $(\mathrm{BMI}) / 95$ th percentile BMI for age, sex, and race] was used to express the degree of obesity. The severity of systolic hypertension and diastolic hypertension were expressed as $\mathrm{SBP}_{\text {score }}$ (systolic $\mathrm{BP} /$ the 95 th percentile systolic BP for age, sex, and height) and $\mathrm{DBP}_{\text {score }}$ (diastolic $\mathrm{BP} /$ the 95 th percentile diastolic $\mathrm{BP}$ for age, sex, and height), respectively. OSAS was defined
\end{abstract}

E. P. Reade $\cdot$ C. Whaley $\cdot$ R. Perkin

Department of Pediatrics, Brody School of Medicine,

East Carolina University,

Greenville, North Carolina, USA

D. Lee

East Carolina Neurology,

Greenville, North Carolina, USA

D. W. McKenney

Department of Pediatrics, Kosair Charities Pediatric Center,

University of Kentucky at Louisville,

Kentucky, USA

\section{J.-J. Lin}

Department of Pediatrics and Communicable Diseases,

University of Michigan,

Ann Arbor, Michigan, USA

\section{J.-J. Lin (-}

Department of Pediatric Nephrology, University of Michigan,

Mott Children's Hospital,

F6865/0297, 1505 Simpson Road East, Ann Arbor,

MI 48109-0297, USA

e-mail: jenlin@umich.edu

Tel.: +1-734-9364210

Fax: +1-734-7636997 as more than one episodes of apnea per hour (AI) or an $\mathrm{O}_{2}$ saturation associated with obstructive apnea of less than $90 \%$. There were 56 obese patients; 42 were hypertensive and 40 patients were diagnosed with OSAS. The incidence of hypertension (68\% vs. $30 \%$ ) and obesity (75\% vs. $52 \%$ ) was higher in OSAS patients than those without OSAS. Compared with the non-obese patients, obese patients had a higher incidence of hypertension or OSAS, a higher $\mathrm{BMI}_{\text {score }}, \mathrm{SBP}_{\text {score }}, \mathrm{DBP}_{\text {score }}, \mathrm{AI}$, hypopnea index $(\mathrm{HI})$, and apnea-hypopnea index (AHI). In obese patients, both $\mathrm{SBP}_{\text {score }}$ and $\mathrm{DBP}_{\text {score }}$ correlated positively with $\mathrm{BMI}_{\text {score }}$, arousal index, and $\mathrm{HI}$. $\mathrm{DBP}_{\text {score }}$ also correlated positively with AHI. Multiple regression analysis showed that HI and $\mathrm{BMI}_{\text {score }}$ were significant independent predictors of $\mathrm{SBP}_{\text {score }}$ or DBP $\mathrm{D}_{\text {score }}$. Obese and hypertensive patients had a higher HI, AHI, and incidence of OSAS (64\% vs. $29 \%$ ) than the obese and normotensive patients. In conclusion, HI had a significant correlation with the degree of hypertension in obese patients, which could not be attributed to the degree of obesity. These findings are consistent with the hypothesis that OSAS is one of the reasons why some obese children are hypertensive and some are not.

Keywords Sleep apnea Hypertension - Hypopnea Obesity

\section{Introduction}

The incidence of obesity has increased significantly in the past 2 decades with an estimated prevalence of $13 \%$ in children aged 6-11 years and 14\% in adolescents aged 12-19 years [1]. In adults, obesity is associated with the development of hypertension [2] and an increased risk of cardiovascular disease (CVD) [3]. Likewise, hypertension is a risk factor for CVD in adults [4]. Since $25 \%-50 \%$ of obese adolescents remain obese into adulthood [5] and childhood hypertension is associated with the future development of systolic hypertension in adulthood [6,7], it is likely that obese children with hypertension will have an increased risk for CVD and morbidity compared with 
those children who are obese but normotensive. Although the long-term outcome of obese children with hypertension is not known, cerebral hemorrhage and heart disease have been described in obese hypertensive adolescents within a 10-year follow-up period [8]. While the association between obesity and hypertension has been attributed to an impaired pressure natriuresis [9], it is not clear why hypertension is not observed in all obese children. Exploration of its mechanisms will allow us to take measures to prevent the development of hypertension in obese children such that their future CVD risk can be reduced.

Obesity is a risk factor for the development of obstructive sleep apnea syndrome (OSAS) in children and adolescents [10,11]. There is an increased incidence of OSAS in obese children [12]. OSAS has also been linked to the development of hypertension in adults, and there is an increased incidence of hypertension in adult patients with OSAS $[13,14]$. Adult patients with OSAS have a higher incidence of hypertension, independent of their age, sex, body mass index (BMI), or waist and neck circumferences, than those without OSAS after a 4-year follow-up period [15]. Epidemiological studies have demonstrated that OSAS is an independent predictor for sustained hypertension in adults [16]. A direct cause-effect link between OSAS and hypertension is supported by the findings that chronic application of continuous positive airway pressure to hypertensive OSAS patients results in reduction of blood pressure (BP) [17, 18]. It is possible that OSAS is associated with an increased risk of hypertension in obese children. To test this hypothesis, we retrospectively reviewed the data of overnight sleep studies in pediatric patients and compared the incidence of OSAS between obese hypertensive children and obese normotensive children.

\section{Materials and methods}

This study was approved by the University and Medical Center Institutional Review Board of East Carolina University, North Carolina. Records of overnight sleep studies between October 2000 and January 2003 from 130 pediatric patients were reviewed. After exclusion of patients with renal failure, transplantation, mental retardation, neuromuscular diseases, diabetes mellitus, chronic lung disease, congenital heart disease, sickle cell disease, or antihypertensive therapy, data from 90 patients were included for analysis. These patients were referred by their primary physicians for sleep study because of their clinical presentation. Their symptoms included daytime hypersomnolence $(72 \%)$, snoring $(91 \%)$, difficult breathing $(30 \%)$, sweating $(11 \%)$, apnea $(36 \%)$, frequent arousal $(13 \%)$, restless sleep $(28 \%)$, and mouth breathing (12\%) during sleep. Patients were interviewed in the sleep clinic where their medical history, weight, height, and manual BP (single measurement according to the guidelines of the 1996 Task Force) were obtained. If the sleep study was indicated, it was performed within 1 month of the clinic visit.

Patients were admitted to the Sleep Center at Pitt County Memorial Hospital (Greenville, N.C.) for overnight polysomnographic (PSG) study performed according to the recommendations of the American Thoracic Society [19]. One parent was asked to stay with the patient. Data from air oronasal flow, electroencephalogram (EEG), electrocardiogram, electrooculogram, tibial and submental electromyogram, chest and abdominal motion, pulse oximeter, and end-tidal $\mathrm{PCO}_{2}$ were recorded continuously on PSG (Nihon Kohden, Japan). Apnea was defined as a greater than $50 \%$ reduction of airflow with a minimum duration of $10 \mathrm{~s}$ and an associated desaturation of $3 \%$ or greater, and/or a sleep arousal. Hypopnea was defined as a $20 \%-50 \%$ reduction in airflow with a minimum duration of $10 \mathrm{~s}$ and an associated desaturation of $3 \%$ or greater, and/or a sleep arousal. EEG arousal was defined as a higher frequency shift in EEG lasting more than $3 \mathrm{~s}$. The arousal index was the number of EEG arousals per hour of sleep as a result of apnea, periodic limb movement, or snoring. The sampling rate of the pulse oximeter was $1 / \mathrm{s}$. Maximal $\mathrm{O}_{2}$ desaturation (\%) was the maximal decline in oxygen saturation from the baseline level during sleep. The apnea index (AI) was the episodes of central, mixed, and obstructive apnea per hour of sleep. The hypopnea index (HI) was the episodes of hypopnea per hour of sleep. The apnea-hypopnea index (AHI) was the sum of $\mathrm{AI}$ and $\mathrm{HI}$. Patients were diagnosed with OSAS if the AI was $>1$ or if the lowest $\mathrm{O}_{2}$ saturation associated with obstructive apnea was less than $90 \%$, as suggested by Marcus et al. [20].

Hypertension was defined as systolic (SBP) or diastolic blood pressure (DBP) equal to or greater than 95th percentile for age, sex, and height according to the reference values of Rosner et al. [21] Obesity was defined as a BMI equal to or greater than the 95th percentile for age, sex, and race according to the published data for American children $[22,23]$. To express the degree of obesity, we used the BMI score (BMI score), which is the ratio of BMI to the 95th percentile BMI for age, sex, and race in this study. Similarly, we used SBP score $\left(\mathrm{SBP}_{\text {score }}\right)$, which is the ratio of systolic $\mathrm{BP}$ to the 95th percentile systolic BP for age, sex, and height, and DBP score $\left(\mathrm{DBP}_{\text {score }}\right)$, which is the ratio of diastolic $\mathrm{BP}$ to the 95 th percentile diastolic BP for age, sex, and height, to express the severity of hypertension.

\section{Statistics}

All data are mean \pm SD. Yates corrected chi-squared test or MannWhitney U test was used to compare the difference between two groups when appropriate. Spearman's rank order test was used to examine correlations between the variables. Forward stepwise multiple regression analysis was used to examine significant in dependent predictors of the dependent variable. A $P<0.05$ was considered statistically significant.

\section{Results}

The mean age of the 58 males and 32 females studied was 10.7 years (range $4.2-18.8$ years). Their BMI was $28.2 \pm 11.1 \mathrm{~kg} / \mathrm{m}^{2}$. There were 58 African-American patients, 31 Caucasians, and 1 of Hispanic origin; 25 patients had a history of asthma. There were 56 obese patients $(62 \%)$ and $42(47 \%)$ had either systolic or diastolic hypertension.

Forty patients $(44 \%)$ were diagnosed with OSAS. All OSAS patients had symptoms of snoring and/or hypersomnolence. There was no significant difference between patients with $(n=40)$ and without $(n=50)$ OSAS in their age $(10.0 \pm 3.9$ vs. $11.2 \pm 3.6$ years), sex (male/female $29 / 11$ vs. 29/21), race (Caucasian/African-American 12/27 vs. $19 / 31)$, and the percentage of patients with asthma (23\% vs. $32 \%)$. As shown in Table 1 , the incidences of hypertension $(68 \%)$ and obesity $(75 \%)$ was significantly higher in OSAS patients, as demonstrated by their higher $\mathrm{BMI}_{\text {score }}, \mathrm{SBP}_{\text {score }}$, and $\mathrm{DBP}_{\text {score }}$. Of OSAS patients, there were 14 patients with isolated systolic hypertension, 4 
Table 1 Demographic data of patients with or without obstructive sleep apnea syndrome (OSAS) (BMI body mass index, $S B P$ systolic blood pressure, $D B P$ diastolic blood pressure)

\begin{tabular}{lcc}
\hline & Non-OSAS $(n=50)$ & OSAS $(n=40)$ \\
\hline Hypertension, $n(\%)$ & $15(30 \%)$ & $27(68 \%)^{* *}$ \\
Obesity, $n(\%)$ & $26(52 \%)$ & $30(75 \%)^{*}$ \\
BMI $_{\text {score }}$ & $1.03 \pm 0.32$ & $1.27 \pm 0.40 * *$ \\
SBP $_{\text {score }}$ & $0.94 \pm 0.11$ & $0.99 \pm 0.12^{*}$ \\
DBP $_{\text {score }}$ & $0.84 \pm 0.12$ & $0.93 \pm 0.14 * *$ \\
\hline
\end{tabular}

$* P<0.05, * * P<0.005, * * * P<0.0005$ vs. non-OSAS patients $\mathrm{BMI}_{\text {score }}$ is the ratio of BMI to the 95th percentile BMI for age, sex, and race

$\mathrm{SBP}_{\text {score }}$ is the ratio of systolic BP to the 95 th percentile systolic BP for age, sex, and height

$\mathrm{DBP}_{\text {score }}$ is the ratio of diastolic BP to the 95 th percentile diastolic BP for age, sex, and height

Table 2 Correlation coefficients between BP scores and demographic or polysomnographic data in all patients $(n=90)(A I$ apnea index, $H I$ hypopnea index, $A H I$ apnea-hypopnea index)

\begin{tabular}{|c|c|c|c|}
\hline & $\mathrm{SBP}_{\text {score }}$ & $\mathrm{DBP}_{\text {score }}$ & $\mathrm{BMI}_{\text {score }}$ \\
\hline $\mathrm{BMI}_{\text {score }}, 1.14 \pm 0.38$ & $0.62 * * *$ & $0.60 * * *$ & - \\
\hline Arousal index, $1.57 \pm 1.20$ & $0.49 * * *$ & $0.45 * * *$ & $0.77 * * *$ \\
\hline AI, $4.74 \pm 9.07$ & 0.08 & 0.19 & 0.09 \\
\hline HI, $2.72 \pm 5.17$ & $0.39 * * *$ & $0.42 * * *$ & $0.44 * * *$ \\
\hline AHI, $7.45 \pm 12.28$ & $0.27 *$ & $0.35 * *$ & $0.29 * *$ \\
\hline
\end{tabular}

$* P<0.05, * * P<0.005, * * * P<0.0005$

Arousal index is the number of arousal as a result of periodic limb movement or snoring per hour of sleep

AI is the episodes of apnea per hour of sleep

$\mathrm{HI}$ is the episodes of hypopnea per hour of sleep

$\mathrm{AHI}$ is the sum of $\mathrm{AI}$ and $\mathrm{HI}$

with isolated diastolic hypertension, and 9 with combined systolic and diastolic hypertension. The prevalence of systolic (58\%) and diastolic (33\%) hypertension among patients with OSAS and hypertension was not significantly different $(P=0.28)$.

Correlation analysis of all patients is presented in Table 2. There was no correlation between $\mathrm{BMI}_{\text {score}}$, $\mathrm{SBP}_{\text {score }}, \mathrm{DBP}_{\text {score }}$, or any PSG variable with age (data not shown). There was no correlation between the maximal $\mathrm{O}_{2}$ desaturation and $\mathrm{SBP}_{\text {score }}, \mathrm{DBP}_{\text {score }}$, or $\mathrm{BMI}_{\text {score }}$. Both $\mathrm{SBP}_{\text {score }}$ and $\mathrm{DBP}_{\text {score }}$ correlated positively with $\mathrm{BMI}_{\text {score }}$, arousal index, $\mathrm{HI}$, and AHI. Similarly, $\mathrm{BMI}_{\text {score }}$ correlated positively with arousal index, HI, and AHI. To examine the independent predictors of $\mathrm{SBP}_{\text {score }}$ or $\mathrm{DBP}_{\text {score }}$, forward stepwise multiple regression analysis was performed in all patients using $\mathrm{BMI}_{\text {score}}$, arousal index, $\mathrm{HI}$, and $\mathrm{AHI}$ as independent variables. Data of these PSG variables were $\log$ transformed $\left[\log _{10}(\right.$ data +1$\left.)\right]$ before the analysis because of their skewed distribution. For $\mathrm{SBP}_{\text {score, }}$ this model explained $40 \%$ of its variability. $\mathrm{BMI}_{\text {score }}$ was the only significant predictor of $\mathrm{SBP}_{\text {score }}$, which explained $38 \%$ of its variability $(\beta=0.55, P=0.000)$. For $\mathrm{DBP}_{\text {score }}$, this model explained $38 \%$ of its variability. $\mathrm{BMI}_{\text {score }}$ alone explained $35 \%$ of variability $(\beta=0.51, P=0.000)$. The addition of $\mathrm{HI}$ explained another $3 \%$ of variability that was significant $(\beta=0.19, P=0.044)$. These results in-
Table 3 Demographic and polysomnographic data of non-obese and obese patients

\begin{tabular}{lcl}
\hline & Non-obese $(n=34)$ & Obese $(n=56)$ \\
\hline Hypertension, $n(\%)$ & $3(8 \%)$ & $39(70 \%) * * *$ \\
OSAS, $n(\%)$ & $10(29 \%)$ & $30(54 \%)^{*}$ \\
BMI $_{\text {score }}$ & $0.77 \pm 0.14$ & $1.36 \pm 0.29 * * *$ \\
SBP $_{\text {score }}$ & $0.88 \pm 0.09$ & $1.02 \pm 0.10 * * *$ \\
DBP $_{\text {score }}$ & $0.79 \pm 0.11$ & $0.93 \pm 0.12 * * *$ \\
Arousal index & $1.00 \pm 0.47$ & $1.91 \pm 1.37 * * *$ \\
AI & $4.17 \pm 8.87$ & $5.08 \pm 9.26$ \\
HI & $0.89 \pm 1.54$ & $3.83 \pm 6.20 * * *$ \\
AHI & $5.06 \pm 9.20$ & $8.91 \pm 13.69 *$ \\
\hline
\end{tabular}

$* P<0.05, * * P<0.005, * * * P<0.0005$ vs. non-obese patients

Table 4 Correlation coefficients between BP scores and demographic or polysomnographic data of obese patients $(n=56)$

\begin{tabular}{llll}
\hline & $\mathrm{SBP}_{\text {score }}$ & $\mathrm{DBP}_{\text {score }}$ & $\mathrm{BMI}_{\text {score }}$ \\
\hline BMI $_{\text {score }}$ & $0.33^{*}$ & $0.37^{* *}$ & - \\
Arousal index & $0.32^{*}$ & $0.28^{*}$ & $0.67 * * *$ \\
$\begin{array}{l}\text { Maximal } \mathrm{O}_{2} \text { desaturation } \\
(\%)\end{array}$ & 0.04 & 0.13 & $0.31^{*}$ \\
$\mathrm{AI}$ & & & \\
$\mathrm{HI}$ & 0.03 & 0.23 & 0.14 \\
$\mathrm{AHI}$ & $0.34^{*}$ & $0.44^{* *}$ & 0.25 \\
& 0.20 & $0.40^{* *}$ & $0.28^{*}$ \\
\hline
\end{tabular}

$* P<0.05, * * P<0.005, * * * P<0.0005$

dicate that $\mathrm{BMI}_{\text {score }}$ was a determinant of $\mathrm{SBP}_{\text {score }}$ or $\mathrm{DBP}_{\text {score }}$ among the variables examined. Although $\mathrm{HI}$ was another significant determinant of $\mathrm{DBP}_{\text {score, }}$, it only accounted for a small amount of variability.

Data of non-obese and obese patients are shown in Table 3. There was no significant difference between their age, male/female ratio, racial distribution, incidence of asthma, or maximal $\mathrm{O}_{2}$ desaturation during sleep (data not shown). Compared with non-obese patients, obese patients had a higher incidence of hypertension $(70 \%)$ and OSAS (54\%) and a higher $\mathrm{BMI}_{\text {score }}, \mathrm{SBP}_{\text {score }}, \mathrm{DBP}_{\text {score }}$, arousal index, HI, and AHI. Of the 39 obese patients with hypertension, 25 had OSAS (64\%) and 2 of the 3 nonobese patients with hypertension had OSAS. Of the obese patients, 22 had isolated systolic hypertension, 13 had both systolic and diastolic hypertension, and 4 had isolated diastolic hypertension. In the non-obese group, 1 patient had isolated systolic hypertension, 1 patient had both systolic and diastolic hypertension, and 1 patient had isolated diastolic hypertension. Obese patients had a higher incidence of systolic hypertension $(63 \%$ vs. $6 \%$, $P<0.05)$, diastolic hypertension $(30 \%$ vs. $6 \%, P<0.05)$, and OSAS $(54 \%$ vs. $29 \%, P<0.05)$ than the non-obese patients.

The correlation analysis of BP and other variables in obese patients is presented in Table 4. Both $\mathrm{SBP}_{\text {score }}$ and $\mathrm{DBP}_{\text {score }}$ correlated positively with $\mathrm{BMI}_{\text {score, }}$, arousal index, and HI. In addition, $\mathrm{DBP}_{\text {score }}$ correlated positively with AHI. BMI $_{\text {score }}$ correlated positively with arousal index, maximal $\mathrm{O}_{2}$ desaturation, and AHI. There was no correlation between age and $\mathrm{SBP}_{\text {score }}, \mathrm{DBP}_{\text {score }}$, or $\mathrm{BMI}_{\text {score }}$ (data not shown). Forward stepwise multiple 
Table 5 Demographic and polysomnographic data of obese patients with or without hypertension

\begin{tabular}{lll}
\hline & Normotensive $(n=17)$ & Hypertensive $(n=39)$ \\
\hline OSAS, $n(\%)$ & $5(29 \%)$ & $25(64 \%)^{*}$ \\
SBP $_{\text {score }}$ & $0.91 \pm 0.06$ & $1.06 \pm 0.07 * * *$ \\
DBP $_{\text {score }}$ & $0.84 \pm 0.07$ & $0.97 \pm 0.11 * * *$ \\
Arousal index & $1.79 \pm 1.14$ & $1.96 \pm 1.47$ \\
AI & $3.66 \pm 7.35$ & $5.70 \pm 10.00$ \\
HI & $1.58 \pm 3.17$ & $4.80 \pm 6.94 * *$ \\
AHI & $5.24 \pm 8.85$ & $10.5 \pm 15.2 *$ \\
\hline
\end{tabular}

$* P<0.05, * * P<0.005, * * * P<0.0005$ vs. normotensive patients

regression analysis for the determinants of $\mathrm{SBP}_{\text {score }}$ and $\mathrm{DBP}_{\text {score }}$ was performed using $\mathrm{BMI}_{\text {score }}$, arousal index, $\mathrm{HI}$, and $\mathrm{AHI}$ as independent variables. Data of these PSG variables were $\log$ transformed $\left[\log _{10}(\right.$ data +1$\left.)\right]$ before the analysis because of their skewed distribution. For $\mathrm{SBP}_{\text {score }}$, this model explained $23 \%$ of its variability. $\mathrm{BMI}_{\text {score }}$ alone accounted for $14 \%$ of the variability ( $\beta=0.33, P=0.004)$. Addition of $\mathrm{HI}$ added another $7 \%$ of variability $(\beta=0.42)$, which was significant $(P=0.04)$. For $\mathrm{DBP}_{\text {score }}$, this model accounted for a total of $28 \%$ variability. HI alone explained $18 \%$ of the variability $(\beta=0.32$, $P=0.01)$. Addition of $\mathrm{BMI}_{\text {score }}$ explained another $10 \%$ of the variability in $\mathrm{DBP}_{\text {score }}$, which was significant $(\beta=0.34$, $P=0.001)$. In non-obese patients, except for a positive correlation between $\mathrm{BMI}_{\text {score }}$ and arousal index, there was no correlation of $\mathrm{SBP}_{\text {score }}, \mathrm{DBP}_{\text {score }}$, or $\mathrm{BMI}_{\text {score }}$ with any of the PSG variables examined (data not shown).

We next compared the data of hypertensive and normotensive patients in the obese group. There was no difference in their age $(11.0 \pm 3.4$ vs. $11.1 \pm 4.0$ years $)$, sex (male/female $24 / 15$ vs. 11/6), race (Caucasian/AfricanAmerican $12 / 27$ vs. $7 / 10)$, incidence of asthma (26\% vs. $24 \%), \mathrm{BMI}_{\text {score }}(1.38 \pm 0.3$ vs. $1.30 \pm 0.28)$, or maximal $\mathrm{O}_{2}$ desaturation $(10.3 \pm 7.9$ vs. $9.97 \pm 8.8 \%)$. As shown in Table 5 , obese and hypertensive patients had a higher incidence of OSAS $(64 \%)$ than the obese and normotensive patients (29\%). Among the PSG variables examined, higher $\mathrm{HI}$ and $\mathrm{AHI}$ were seen in hypertensive patients. Both $\mathrm{HI}$ and $\mathrm{BMI}_{\text {score }}$ were significant independent predictors of $\mathrm{SBP}_{\text {score }}$ and $\mathrm{DBP}_{\text {score }}$.

\section{Discussion}

There are only a few studies examining the association of hypertension and OSAS in pediatric patients. Guilleminault et al. [24] reported five children with sleep apnea and hypertension. BP was normalized after tonsillectomy and adenoidectomy ( $\mathrm{T}$ and $\mathrm{A}$ ) in three patients and after tracheotomy in two patients. Serratto et al. [25] described three pediatric patients with severe hypertension and right heart failure. Two had normal BP after $\mathrm{T}$ and $\mathrm{A}$ and the other after tracheotomy. Ross et al. [26] described the resolution of left ventricular hypertrophy and a reduced antihypertensive medication after $\mathrm{T}$ and $\mathrm{A}$ and tracheotomy in one child with sleep apnea. While these reports support a link between OSAS and hypertension, cases are few and most have severe OSAS and hypertension. Marcus et al. [20] examined the nocturnal BP in 41 children with OSAS $(\mathrm{AI} \geq 3)$ and 26 children with primary snoring. $\mathrm{BP}_{\text {index }}$ was calculated as the difference between the measured BP and the 95th percentile BP for age, gender, and height. A higher $\mathrm{DBP}_{\text {index }}$, but not $\mathrm{SBP}_{\text {index }}$, was found in OSAS children during wakefulness or sleep. $\mathrm{BMI}$ was an independent predictor of $\mathrm{SBP}_{\text {index }}$ while age, $\mathrm{AI}$, and $\mathrm{BMI}$ were independent predictors of $\mathrm{DBP}_{\text {index }}$. It was concluded that the degree of diastolic hypertension is related to the severity of OSAS and the degree of obesity. Kohyama et al. [27] studied nocturnal BP in 23 children. Higher $\mathrm{SBP}_{\text {index }}$ and $\mathrm{DBP}_{\text {index }}$ were noted in those children with an AHI of more than 10. Age, BMI, and AHI were significant predictors of $\mathrm{SBP}_{\text {index }}$ during REM sleep. It was concluded that nocturnal SBP correlated with the degree of OSAS.

To the best of our knowledge, the present study is the first to examine the association between office BP and OSAS in obese children. Similar to the findings of Marcus et al. [20] and Kohyama et al. [27], BMI was a significant determinant of SBP and DBP in our study when both obese and non-obese patients were included in the analysis. However, instead of AI or AHI, we found HI was a significant predictor of $\mathrm{DBP}_{\text {score }}$ in all patients. This discrepancy may be related to the following factors. Our study examined the daytime office BP when patients were not sleeping, while their studies examined nocturnal BP at the time of OSAS. Circadian changes in BP may affect the results of analysis. Our definition of hypopnea is different from that of Marcus et al. [20], which could have affected the incidence and results of sleep studies [28]. A significant proportion of our patients were obese $(62 \%)$, which is higher than that the $13 \%$ in the study of Kohyama et al. [27] and the $27 \%$ in the study of Marcus et al. [20]. Furthermore, it has been shown that children with OSAS usually present with prolonged periods of partial upper airway obstruction and fewer and shorter episodes of complete obstruction [29, 30]. It should be noted that while the use of $\mathrm{BP}_{\text {index }}$ by these investigators was to avoid the age difference in $\mathrm{BP}$ levels, $\mathrm{SBP}_{\text {index }}$ or $\mathrm{DBP}_{\text {index }}$ was still related to age in their studies. In our study, $\mathrm{SBP}_{\text {score }}, \mathrm{DBP}_{\text {score }}$, or $\mathrm{BMI}_{\text {score }}$ was not related to age.

We observed a high incidence of obesity $(75 \%)$ in patients with OSAS (Table 1). This is comparable to the reported $60 \%-70 \%$ incidence of obesity in adults with OSAS [31]. Mallory et al. [32] described obesity in $37 \%$ of 41 children with a history suggestive of OSAS. However, obesity was defined as a body weight more than $150 \%$ ideal weight in their study, which is different from our criteria for obesity. In our patients, $\mathrm{BMI}_{\text {score }}$ correlated positively with arousal index, HI, or AHI. This is consistent with the study of Redline et al. [10], which reported that obesity is a risk factor for OSAS. Mechanisms underlying the association between obesity and OSAS are not clear. It has been hypothesized that obesity affects breathing during sleep through alteration of upper 
airway structure and function, obesity related hypoxemia, or an abnormal ventilatory drive [33].

The incidence of hypertension in our patients with OSAS was 68\% (Table 1). Guilleminault et al. [34] reported an incidence of hypertension of $8 \%$ in 50 children with OSAS. However, 26 of these children had underlying anatomical or neuromuscular disorders that could have affected their BP levels. The difference in BP reference values between their study and ours could also have contributed to the difference in the incidence of hypertension. In our study, HI was a significant independent predictor of $\mathrm{DBP}_{\text {score }}$ when all patients were included for analysis. Results from the Wisconsin study [16] suggest that AHI is an independent risk factor for hypertension. Our findings are comparable to theirs since hypopnea is a more-common presentation than apnea in children with OSAS $[29,30]$. Experiments in dogs have demonstrated a direct cause-effect relationship between OSAS and a sustained daytime hypertension [35]. Episodic hypoxia in rats resulted in sustained hypertension that could be blocked by carotid body denervation, sympathetic nerve ablation, renal sympathectomy, adrenal medullectomy, and an angiotensin-1 receptor blocker, suggesting an overactivity of the adrenergic and renin-angiotensin system from intermittent hypoxia [36]. An increased sympathetic drive as a result of intermittent hypoxia [37] and/ or arousal [38] has been linked to the development of hypertension in adults with OSAS. Treatment with continuous positive airway pressure in adults with OSAS decreases their sympathetic nerve activity $[39,40]$. Other hypothesized mechanisms underlying the association between OSAS and hypertension include dysfunction of the vascular endothelium [41], altered corticotropic function [42], and insulin resistance [43].

The degree of obesity correlated strongly with the severity of systolic or diastolic hypertension when both our obese and non-obese patients were included for analysis (Table 2). An impaired renal pressure natriuresis has been suggested to play a central role in obesity induced hypertension [9]. Factors such as insulin resistance, endothelial dysfunction, activation of the renin-angiotensin system, increased sympathetic nervous system activity, renal structural changes, or altered hypothalamicpituitary-adrenal axis have been implicated in its pathogenesis [44]. It is noteworthy that these pathogenic factors are very similar to those described earlier for the hypertension in OSAS. The interactions between mechanisms underlying the association between obesity and hypertension and the association between OSAS and hypertension are likely complicated and remain to be elucidated.

The incidence of OSAS in our obese patients was $54 \%$ (Table 3). Silvestri et al. [45] reported OSAS in 59\% of 32 obese children. Kahn et al. [46] reported that seven of ten overweight infants have disordered breathing during sleep. Our data are comparable to theirs. In our obese patients (Table 4), HI was a significant independent predictor of $\mathrm{SBP}_{\text {score }}$ and $\mathrm{DBP}_{\text {score }}$. Although $\mathrm{BMI}_{\text {score }}$ was also a significant independent predictor of both BP scores, there was no significant difference in $\mathrm{BMI}_{\text {score }}$ between normotensive and hypertensive obese patients (Table 5). These findings suggest that, in addition to BMI, hypopnea correlates significantly with the degree of hypertension in our obese patients. Although these findings do not necessarily indicate a cause-effect relationship between hypopnea and the development of hypertension in these patients, they are consistent with the hypothesis that OSAS may play a significant role and may explain why only some obese children are hypertensive.

It has been suggested that the baseline BP is variable among individuals, due to genetic differences or other factors that influence BP regulation. An increase in BP from weight gain results in different BP levels in the population, and so some are hypertensive and some are not according to the population standard [44]. This hypothesis is supported by the finding that weight loss reduces $\mathrm{BP}$ in adults with a high or normal BP [47], although this BPlowering effect of weight loss is not observed in every adult [48]. Another possibility is that while the baseline BP levels are similar among individuals with the same body mass, different individuals respond differently to weight gain due to genetic factors. Our findings are not necessarily at variance with these hypotheses. Genetic factors, such as family clustering [49], human leukocyte antigen typing [50], and ethnicity [10], have been implicated in the pathophysiology of OSAS. Different genetic risk for OSAS results in different baseline BP levels in children. An increase in BP due to obesity results in different BP levels in the population, such that some children are hypertensive and some are not according to the population standard. An alternative explanation for our observation is that obesity causes some children with genetic risks for OSAS to develop significant hypopnea during sleep. This in turn elevates their BP further. This, however, remains to be validated.

In summary, our study demonstrates that the degree of obesity is a significant determinant of PSG variables and the severity of systolic and diastolic hypertension in our patients. In our obese patients, there is a higher incidence of OSAS in those who are hypertensive compared with those who are normotensive. In addition, the HI during sleep is a significant determinant of the severity of systolic or diastolic hypertension. These findings are consistent with the hypothesis that OSAS is one of the reasons why some children are hypertensive and some are not. It should be noted that our data are based on a referral population. The findings are not necessarily applicable to the general population. Prospective studies, both crosssectional and longitudinal, on a non-selected population of children are needed to confirm our findings.

\section{References}

1. National Center for Health Statistics (2001) Prevalence of overweight among children and adolescents, United States, 1999. Center for Disease Control 
2. Alpert MA, Hashimi MW (1993) Obesity and the heart. Am J Med Sci 306:117-123

3. Calle EE, Thun MJ, Petrelli JM, Rodriguez C, Heath CW Jr (1999) Body-mass index and mortality in a prospective cohort of US adults. N Engl J Med 341:1097-1105

4. MacMahon SW, Peto R, Cutler J, Collins R, Sorlie P, Neaton J, Abbott R, Godwin J, Dyer A, Stamler J (1990) Blood pressure, stroke, and coronary heart disease. 1. Prolonged differences in blood pressure: prospective observational studies corrected for the regression dilution bias. Lancet 335:765-774

5. Dietz W, Robinson T (1993) Assessment and treatment of childhood obesity. Pediatr Rev 14:337-344

6. Louer RM, Clarke WR (1988) A longitudinal review of blood pressure during childhood: the Muscatine Study. Stat Med 7:47-57

7. Higgins MW, Keller JB, Metzner HL, Moore FE, Ostrander LD $\mathrm{Jr}$ (1980) Studies of blood pressure in Tecumseh, Michigan. II. Antecedents of childhood high blood pressure in young adults. Hypertension 2:117-123

8. Heyden S, Bartel AG, Hames CG, McDonough JR (1969) Elevated blood pressure levels in adolescents, Evans County, Georgia. JAMA 209:1683-1689

9. Hall JE (1997) Mechanisms of abnormal renal sodium handling in obesity hypertension. Am J Hypertens 10:49S-55S

10. Redline S, Tishler PV, Schluchter M, Aylor J, Clark, K, Graham G (1999) Risk factors for sleep-disordered breathing in children. Association with obesity, race, and respiratory problems. Am J Respir Crit Care Med 159:1527-1532

11. Stepanski E, Zayyad A, Nigro C, Lopata M, Basner R (1999) Sleep-disordered breathing in a predominantly African American pediatric population. J Sleep Res 8:65-70

12. Chay OM, Goh A, Abisheganaden J, Tang J, Lim WH, Chan YH, Wee MK, Johan A, Cheng HK, Lin M, Chee T, Rajan U, Wang S, Machin D (2000) Obstructive sleep apnea syndrome in obese Singapore children. Pediatr Pulmonol 29:284-290

13. Hoffstein V, Chan CK, Stutsky AS (1991) Sleep apnea and systemic hypertension: a causal association review. Am J Med 91:190-196

14. Hla KM, Young TB, Bidwell T, Palta M, Skatrud JB, Dempsey J (1994) Sleep apnea and hypertension-a population-based study. Ann Intern Med 120:382-388

15. Peppard PE, Young TY, Palta M, Skatrud J (2000) Prospective study of the association between sleep-disordered breathing and hypertension. N Engl J Med 342:1378-1384

16. Young T, Finn L, Hla KM, Morgan B, Palta M (1996) Snoring as part of a dose-response relationship between sleep-disordered breathing and blood pressure. Sleep 19:S202-S205

17. Wilcox I, Grunstein RR, Hedner JA, Doyle J, Collins FL, Fletcher PJ, Kelly DT, Sullivan CE (1993) Effects of nasal continuous positive airway pressure during sleep on 24-hour blood pressure in obstructive sleep apnea. Sleep 16:539-544

18. Mayer J, Backer H, Brandenburg U, Penzel T, Peter JH, Wichert P von (1991) Blood pressure and sleep apnea: results of long-term nasal continuous positive airway pressure therapy. Cardiology 79:84-92

19. The official statement of the American Thoracic Society July 1995 (1996) Standards and indications for cardiopulmonary sleep studies in children. Am J Respir Crit Care Med 153:866878

20. Marcus CL, Greene MG, Carroll JL (1998) Blood pressure in children with obstructive sleep apnea. Am J Respir Crit Care Med 157:1098-1103

21. Rosner B, Prineas RJ, Loggie JMH, Daniels SR (1993) Blood pressure nomograms for children and adolescents, by height, sex, and age, in the United States. J Pediatr 123:871-886

22. Rosner B, Prineas R, Loggie JMH, Daniels SR (1998) Percentiles for body mass index in U.S. children 5 to 17 years of age. J Pediatr 132:211-222

23. National Center for Chronic Disease Prevention and Health Promotion (2000) Center for Disease Control

24. Guilleminault CG, Eldridge FL, Simmons FB, Dement WC (1976) Sleep apnea in eight children. Pediatrics 58:23-30
25. Serratto M, Harris VJ, Carr I (1981) Upper airway obstruction. Presentation with systemic hypertension. Arch Dis Child $56: 153-155$

26. Ross RD, Daniels SR, Loggie JMH, Meyer RA, Ballard ET (1987) Sleep apnea-associated hypertension and reversible left ventricular hypertrophy. J Pediatr 111:253-255

27. Kohyama J, Ohinata JS, Hasegawa T (2003) Blood pressure in sleep disordered breathing. Arch Dis Child 88:139-142

28. Manser RL, Rochford P, Pierce RJ, Byrnes GB, Campbell DA (2001) Impact of different criteria for defining hypopneas in the apnea-hypopnea index. Chest 120:909-914

29. Konno A, Togawa K, Hoshino T (1980) The effect of nasal obstruction in infancy and early childhood upon ventilation. Laryngoscope 90:699-707

30. Agency for Health Care Policy and Research. Polysomnography and Sleep Disorders Center (1992) Health Technology Assessment Reports, 1991, no. 4. U.S. Department of Health and Human Services, Washington, DC. US DHHS Publication no. $92-0027$

31. Guilleminault C (1983) Clinical features and evaluation of obstructive sleep apnea. In: Principles and practice of sleep medicine. Saunders, Philadelphia, pp 552-558

32. Mallory GB, Fiser DH, Jackson R (1989) Sleep-associated breathing disorders in morbidly obese children and adolescents. J Pediatr 115:892-897

33. Strobel RJ, Rosen RC (1996) Obesity and weight loss in obstructive sleep apnea: a critical review. Sleep 19:104-115

34. Guilleminault C, Korobin R, Winkle R (1981) A review of 50 children with obstructive sleep apnea syndrome. Lung 159:275-287

35. Brooks D, Horner RL, Kozar LF, Render-Teixeira CL, Phillipson EA (1997) Obstructive sleep apnea as a cause of systemic hypertension. Evidence from a canine model. J Clin Invest 99:106-109

36. Fletcher EC (2000) Effect of episodic hypoxia on sympathetic activity and blood pressure. Respir Physiol 119:189-197

37. Leuenberger U, Jacob E, Sweer L, Waravdekar N, Zwillich C, Sinoway L (1995) Surges of muscle sympathetic nerve activity during obstructive apnea are linked to hypoxemia. J Appl Physiol 79:581-588

38. Loredo JS, Ziegler MG, Ancoli-Israel S, Clausen JL, Dimsdale JE (1999) Relationship of arousals from sleep to sympathetic nervous system activity and BP in obstructive sleep apnea. Chest 116:655-659

39. Narkiewicz K, Kato M, Phillips BG, Pesek CA, Davison DE, Somers VK (1999) Nocturnal continuous positive airway pressure decreases daytime sympathetic traffic in obstructive sleep apnea. Circulation 100:2332-2335

40. Waravdekar NV, Sinoway LI, Zwillich CW, Leuenberger UA (1996) Influence of treatment on muscle sympathetic nerve activity in sleep apnea. Am J Respir Crit Care Med 153:13331338

41. Carlson JT, Rangemark C, Hedner JA (1996) Attenuated endothelium-dependent vascular relaxation in patients with sleep apnea. J Hypertens 14:577-584

42. Bratel T, Wennlund A, Carlstrom K (1999) Pituitary reactivity, androgens and catecholamines in obstructive sleep apnea: effects of continuous positive airway pressure (CPAP). Respir Med 93:1-7

43. Strohl KP, Novak RD, Singer W, Cahan C, Boehm KD, Denko CW, Hoffstem VS (1994) Insulin levels, blood pressure and sleep apnea. Sleep 17:614-618

44. Hall JE, Brands MW, Jones DW, Shek EW, Henegar J (1999) Mechanisms of obesity hypertension and relevance to essential hypertension. In: Obesity, impact on cardiovascular disease. Futura, Armonk, pp 133-153

45. Silvestri JM, Weese-Mayer DE, Bass MT, Kenny AS, Hauptman SA, Pearsall SM (1993) Polysomnography in obese children with a history of sleep-associated breathing disorders. Pediatr Pulmonol 16:124-126

46. Kahn A, Mozin MJ, Rebuffat E, Sottiaux M, Burniat W, Shepherd S, Muller MF (1989) Sleep pattern alterations and 
brief airway obstructions in overweight infants. Sleep 12:430438

47. Whelton PK, Kumanyika SK, Cook NR, Cutler JA, Borhani NO, Hennekens $\mathrm{CH}$, Kuller LH, Langford $\mathrm{H}$, Jones DW, Satterfield S, Lasser NL, Cohen JD for the Trials of Hypertension Prevention Collaborative Research Group (1997) Efficacy of nonpharmacologic interventions in adults with highnormal blood pressure: results from phase 1 of the trials of hypertension prevention. Am J Clin Nutr 65 [Suppl]:652S$660 \mathrm{~S}$

48. The Trials of Hypertension Prevention Collaboroative Research Group (1997) Effects of weight loss and sodium reduction in- tervention on blood pressure and hypertension incidence in overweight people with high-normal blood pressure. The Trials of Hypertension Prevention, phase II. Arch Intern Med 157: 657-667

49. Redline S, Leitner J, Arnold J, Tishler PV, Altose MD (1997) Ventilatory-control abnormalities in familial sleep apnea. Am J Respir Crit Care Med 156:155-160

50. Yoshizawa T, Akashiba T, Kurashina K, Otsuka K, Horie T (1993) Genetics and obstructive sleep apnea syndrome: a study of human leukocyte antigen (HLA) typing. Intern Med 32:9497 